\title{
Urinary Alpha- and Pi-Glutathione S-Transferases in Adult Patients with Type 1 Diabetes
}

\author{
Bernt Johan von Scholten ${ }^{a} \quad$ Simone Theilade ${ }^{a} \quad$ Maria Lajer $^{a}$ \\ Peter Rossing ${ }^{\mathrm{a}-\mathrm{c}}$ \\ ${ }^{a}$ Steno Diabetes Center, Gentofte, ${ }^{b}$ Aarhus University, Aarhus, and ' University of \\ Copenhagen, Copenhagen, Denmark
}

\section{Key Words}

Glutathione S-transferase · Diabetes · Biomarkers · Proximal and distal tubular damage

\begin{abstract}
Background/Aims: Glutathione S-transferases (GSTs) are cytosolic enzymes excreted from renal tubules following tubular damage. $\alpha$-GST primarily originates from proximal tubules, while $\pi$-GST from distal tubules and collecting ducts. We investigated if GST levels are associated with renal function in patients with type 1 diabetes. Methods: We conducted a crosssectional study including 189 Caucasian patients with type 1 diabetes and 16 nondiabetic controls. $\alpha$ - and $\pi$-GST were measured by ELISA and reported as GST/urinary creatinine excretion $(\mu \mathrm{g} / \mathrm{mmol})$. Results: The subjects were $53 \pm 14$ years old, $66(35 \%)$ were female and the estimated glomerular filtration rate was $85 \pm 29 \mathrm{ml} / \mathrm{min} / 1.73 \mathrm{~m}^{2}$. Normo- (<30 mg/24 h), micro- (30-299 mg/24 h) and macroalbuminuria ( $\geq 300 \mathrm{mg} / 24 \mathrm{~h}$ ) was present in 57,61 and 71

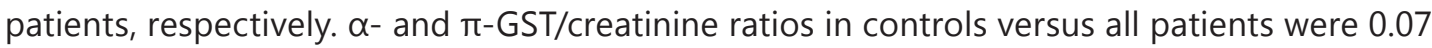
$(0-0.3)$ and $0.11(0-0.8) \mu \mathrm{g} / \mathrm{mmol}$ versus $0.05(0-2.3)$ and $0.16(0-4.9) \mu \mathrm{g} / \mathrm{mmol}(\mathrm{p} \geq 0.16$; ad-

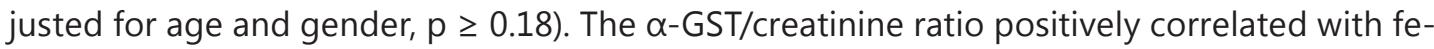

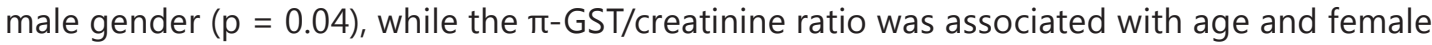
gender $(p \leq 0.016)$. Comparing normo-, micro- and macroalbuminuric patients, $\alpha$ - and $\pi$-GST levels were similar $(p=0.10$; adjusted $p=0.11)$. Neither $\alpha$ - nor $\pi$-GST levels were significant-

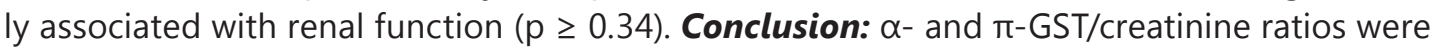
similar among controls and patients with type 1 diabetes. In addition, we did not find associations with albuminuria degree or level of renal function. The significance of increased or decreased excretion of $\alpha$ - and $\pi$-GST among patients with diabetes needs to be clarified.
\end{abstract}


von Scholten et al.: Urinary Alpha- and Pi-Glutathione S-Transferases in Adult Patients with Type 1 Diabetes

\section{Introduction}

Diabetic nephropathy (DN) is a devastating complication of diabetes, affecting approximately $25 \%$ of diabetic patients, and it is the most common cause of end-stage renal disease (ESRD) in the Western world [1]. Furthermore, patients with DN are at a higher risk of cardiovascular morbidity and mortality [2]. Although the prognosis for the patients has improved in part due to improved glycemic control [3], aggressive blood pressure control and inhibition of the renin-angiotensin-aldosterone system (RAAS) [4], DN remains to be a significant problem. Early detection and treatment of DN could potentially delay or even prevent the development of ESRD [5].

Although albuminuria is a major marker in predicting patients at risk of developing DN [6], not all patients with albuminuria develop ESRD and the development of impaired renal function in the absence of albuminuria is not uncommon [7], and thus new markers to supplement albuminuria are warranted.

Studies have shown that besides glomerular damage, tubulointerstitial damage plays an important role in the pathogenesis and progression of DN [8]. Recently, markers of proximal tubular damage, such as $\alpha_{1}$ - and $\beta_{2}$-microglobulin, neutrophil gelatinase-associated lipocalin, liver fatty acid-binding protein and kidney injury molecule-1 [9-11], have been shown to be related to the development of DN, although the associations tend to disappear when adjusting for risk factors.

Glutathione S-transferases (GSTs) are cytosolic enzymes found in high concentrations in renal tubules. $\alpha$-GST is primarily expressed in the proximal tubules, while $\pi$-GST is expressed in the distal tubules and collecting ducts [12]. Following tubular damage, GSTs are released into the urine [13].

The aim of this study was to evaluate if levels of $\alpha$-GST and $\pi$-GST, representing markers of distal and proximal tubular damage, respectively, are associated with levels of albuminuria and renal function in adult patients with type 1 diabetes.

\section{Materials and Methods}

\section{Design and Subjects}

From September 2009 until June 2011, Caucasian patients with type 1 diabetes attending the outpatient clinic at the Steno Diabetes Center were invited to enter a cross-sectional study investigating the associations between blood pressure, arterial stiffness, and diabetes complications [14]. Of 1,285 patients invited, 676 patients were included in the study. The cohort was selected to encompass patients with a wide range of albuminuria; hence, 316 patients with normoalbuminuria, 169 with microalbuminuria, and 191 with macroalbuminuria were included. A control group of 51 persons without diabetes was also enrolled in the study.

In a random subset of this cohort, urine samples were collected for the analysis of GSTs. Samples for the measurement of $\alpha$ - and $\pi$-GST were available in 189 (28.0\%) patients (57 normo-, 61 micro- and 71 macroalbuminuric) and 16 (31.4\%) control subjects.

\section{Clinical and Laboratory Methods}

For all patients, blood samples and clinical characteristics were collected. $\mathrm{HbA}_{1 \mathrm{c}}$ was measured by high-performance liquid chromatography [normal range: 4.1-6.4\%, 21-46 $\mathrm{mmol} / \mathrm{mol}$; Variant, Biorad Laboratories, Munich, Germany], plasma cholesterol and serum creatinine concentration by standardized methods. The urinary albumin excretion rate (UAER) was measured in 24-hour urine collections by enzyme immunoassay. Patients were stratified as normoalbuminuric if their UAER was $<30 \mathrm{mg} / 24 \mathrm{~h}$ in two out of three previous 
consecutive measurements resulting from medical records, and on the day of examination. Similarly micro- or macroalbuminuric patients were defined as having a UAER between 30 and $299 \mathrm{mg} / 24 \mathrm{~h}$ or $\geq 300 \mathrm{mg} / 24 \mathrm{~h}$, respectively, without other kidney or urinary diseases. Patients with a history of persistently elevated UAER, subsequently reduced with treatment, were categorized according to historic elevated samples. They were stratified as either normoalbuminuric or albuminuric (UAER $\geq 30 \mathrm{mg} / 24 \mathrm{~h}$ ), based on the above-described samples.

The estimated glomerular filtration rate (eGFR) was calculated by the four-variable modification of diet in renal disease equation [15].

\section{Urine Measurements}

The quantitative analyses of the biomarkers $\alpha$-GST and $\pi$-GST in spot urine samples were performed by ELISA, using the protocol of the $\alpha$-GST EIA (BIO66NEPHA) and the $\pi$-GST EIA (BI085) NEPHKIT ${ }^{\circledR}$ from Argutus Medical, Ireland. The average inter-/intra-assay coefficients of variation for $\alpha$-GST and $\pi$-GST were $6.3 / 2.7 \%$ and $8.6 / 3.1 \%$, respectively. The lower limit of detection for both $\alpha$-GST and $\pi$-GST was $0.3 \mu \mathrm{g} / \mathrm{l}$.

In order to correct for variation in urine concentrations, the biomarker values were calculated relative to the urine creatinine levels.

The study conformed to the Declaration of Helsinki and was approved by the Danish National Committee on Biomedical Research Ethics (2009-056; NCT01171248). All patients gave their written informed consent.

\section{Statistics}

Normally distributed variables are given as means \pm SD, whereas nonnormally distributed variables are given as medians and interquartile ranges and are $\log _{10}$-transformed before analysis.

Univariate and multivariate linear regression compared levels of GSTs with covariates [including age, gender, diabetes duration, $\mathrm{HbA}_{1 \mathrm{c}}$, diastolic blood pressure, mean arterial pressure (MAP), UAER, eGFR, total cholesterol, antihypertensive treatment (AHT) and smoking]. Comparisons between groups were performed by unpaired Student's t test and analysis of variance.

Analysis of covariance was used in multivariate comparisons (adjusted for gender, age and eGFR). A two-tailed $p$ value $<0.05$ was considered significant. Statistical analyses were performed using SPSS for Windows, version 20.0 (SPSS, Chicago, Ill., USA).

\section{Results}

The patients were $53 \pm 14$ years old, and had had diabetes for an average of 28 (1-65) years with an eGFR of $84 \pm 29 \mathrm{ml} / \mathrm{min} / 1.73 \mathrm{~m}^{2} ; 66$ (35\%) of them were female. The controls were $40 \pm 12$ years old and had an eGFR of $100 \pm 19 \mathrm{ml} / \mathrm{min} / 1.73 \mathrm{~m}^{2} ; 6(38 \%)$ of them were female (table 1).

$\alpha$ - and $\pi$-GST in Patients versus Controls

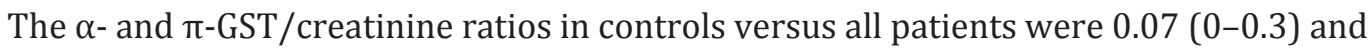
$0.11(0-0.8) \mu \mathrm{g} / \mathrm{mmol}$ versus $0.05(0-2.3)$ and $0.16(0-4.9) \mu \mathrm{g} / \mathrm{mmol}(\mathrm{p} \geq 0.28$; adjusted for age, gender and eGFR, $\mathrm{p} \geq 0.24$ ).

When comparing nondiabetic controls with normoalbuminuric patients, the levels of $\alpha$-GST and $\pi$-GST were similar ( $p \geq 0.38$; adjusted for age, gender and eGFR, $p \geq 0.30$ ). 
von Scholten et al.: Urinary Alpha- and Pi-Glutathione S-Transferases in Adult Patients with Type 1 Diabetes

Table 1. Baseline characteristics for patients according to albuminuria group and controls

\begin{tabular}{|c|c|c|c|c|c|}
\hline & $\begin{array}{l}\text { Controls } \\
(n=16)\end{array}$ & $\begin{array}{l}\text { Normo- } \\
\text { albuminuria } \\
(\mathrm{n}=57)\end{array}$ & $\begin{array}{l}\text { Micro- } \\
\text { albuminuria } \\
(n=61)\end{array}$ & $\begin{array}{l}\text { Macro- } \\
\text { albuminuria } \\
(\mathrm{n}=71)\end{array}$ & $\mathrm{p}$ value \\
\hline Female, \% & 38 & 33 & 34 & 37 & 0.92 \\
\hline Age, years & $40 \pm 12$ & $46 \pm 16$ & $58 \pm 12$ & $56 \pm 10$ & $<0.001$ \\
\hline Diabetes duration, years & $\mathrm{N} / \mathrm{A}$ & $10(1-56)$ & $35(3-65)$ & $37(13-65)$ & $<0.001$ \\
\hline Systolic blood pressure, $\mathrm{mm} \mathrm{Hg}$ & $127 \pm 16$ & $126 \pm 11$ & $133 \pm 17$ & $136 \pm 19$ & 0.004 \\
\hline Diastolic blood pressure, $\mathrm{mm} \mathrm{Hg}$ & $78 \pm 12$ & $76 \pm 10$ & $72 \pm 11$ & $74 \pm 10$ & 0.16 \\
\hline $\mathrm{MAP}, \mathrm{mm} \mathrm{Hg}$ & $94 \pm 13$ & $93 \pm 10$ & $92 \pm 11$ & $94 \pm 13$ & 0.67 \\
\hline $\mathrm{HbA}_{1 \mathrm{c}}, \mathrm{mmol} / \mathrm{mol}$ & $35 \pm 3$ & $60 \pm 14$ & $65 \pm 13$ & $68 \pm 14$ & 0.003 \\
\hline Total cholesterol, mmol/l & $5.1 \pm 0.8$ & $4.6 \pm 0.8$ & $4.7 \pm 1.0$ & $4.7 \pm 1.1$ & 0.61 \\
\hline $\mathrm{eGFR}, \mathrm{ml} / \mathrm{min} / 1.73 \mathrm{~m}^{2}$ & $100 \pm 19$ & $102 \pm 24$ & $84 \pm 27$ & $69 \pm 27$ & $<0.001$ \\
\hline UAER, mg/24 h & $8(2-21)$ & $10(4-44)$ & $35(4-450)$ & $140(4-4,029)$ & $<0.001$ \\
\hline AHT, $\%$ & 6 & 35 & 92 & 99 & $<0.001$ \\
\hline Smoking, \% & 19 & 23 & 25 & 28 & 0.78 \\
\hline$\alpha$-GST/creatinine ratio, $\mu \mathrm{g} / \mathrm{mmol}$ & $0.07(0-0.3)$ & $0.05(0-0.6)$ & $0.05(0-2.3)$ & $0.04(0-0.6)$ & 0.72 \\
\hline$\pi$-GST/creatinine ratio, $\mu \mathrm{g} / \mathrm{mmol}$ & $0.11(0-0.8)$ & $0.15(0-3.4)$ & $0.20(0-3.7)$ & $0.13(0-4.9)$ & 0.12 \\
\hline
\end{tabular}

Values are means \pm SD or medians with ranges in parentheses unless indicated otherwise. $p$ values are for ANOVA for all 4 groups except for diabetes duration and $\mathrm{HbA}_{1 \mathrm{c}}$ where controls are left out.

$\alpha$ - and $\pi$-GST in Patients with Diabetes

The $\alpha$-GST/creatinine ratio was significantly higher in females $[0.06(0-1.9) \mu \mathrm{g} / \mathrm{mmol}]$ than in males [0.04 $(0-2.3) \mu \mathrm{g} / \mathrm{mmol} ; \mathrm{p}=0.04]$, while it was similar in smokers and nonsmokers and in patients with or without AHT ( $\mathrm{p} \geq 0.60)$. It did not correlate with age, diabetes duration, MAP, diastolic blood pressure, total cholesterol, UAER or eGFR ( $p \geq 0.22$ ), but tended to be positively correlated with $\mathrm{HbA}_{1 \mathrm{c}}(\mathrm{p}=0.063)$. In multivariate analyses (including gender, age, diabetes duration, $\mathrm{HbA}_{1 \mathrm{c}}$, MAP, diastolic blood pressure, UAER, eGFR, total cholesterol, AHT and smoking), no correlations were found ( $p>0.10)$.

In contrast, $\pi$-GST correlated positively with age $(p=0.029)$, but not with diabetes duration, $\mathrm{HbA}_{1 \mathrm{c}} \mathrm{MAP}$, diastolic blood pressure, total cholesterol, UAER, eGFR, AHT or smoking ( $p \geq 0.14)$. In addition, $\pi$-GST was significantly higher in females $(p<0.0001)$, while it was similar in smokers and nonsmokers and in patients with or without AHT $(\mathrm{p} \geq$ $0.21)$.

In multivariate analyses (including gender, age, diabetes duration, $\mathrm{HbA}_{1} \mathrm{c}, \mathrm{MAP}$, diastolic blood pressure, UAER, eGFR, total cholesterol, AHT and smoking), $\pi$-GST was only significantly associated with age and female gender $(\mathrm{p} \leq 0.044)$ but not with renal function $(\mathrm{p}=$ $0.27)$.

\section{$\alpha$ - and $\pi$-GST and Albuminuria Degree}

Comparing patients with normo-, micro- and macroalbuminuria revealed similar levels of $\alpha$-GST ( $p=0.89$; adjusted for age, gender and eGFR, $p=0.92$ ) and $\pi-G S T$ ( $p=0.10$; adjusted $\mathrm{p}=0.11$ ). Normoalbuminuric patients compared with micro- and macroalbuminuric patients also had similar levels of both $\alpha$ - and $\pi$-GST ( $p \geq 0.69$; adjusted $\mathrm{p} \geq 0.61$ ). Excluding eGFR from the adjusted analyses did not change the results for $\alpha$-GST and $\pi$-GST (adjusted $p \geq$ 0.064). 
von Scholten et al.: Urinary Alpha- and Pi-Glutathione S-Transferases in Adult Patients with Type 1 Diabetes

\section{Discussion}

In this study including 189 patients with type 1 diabetes and 16 control subjects, we measured the urinary excretion of markers of proximal and distal tubular damage, $\alpha$-GST and $\pi$-GST, to investigate their association with the presence of diabetes and levels of renal function and albuminuria.

The results indicate that the $\alpha$-GST/creatinine ratio was higher in females and tended to be positively associated with $\mathrm{HbA}_{1 c}$; however, after being adjusted the correlations were no longer significant. In contrast, the adjusted $\pi$-GST/creatinine ratio remained positively associated with age and female gender. However, no other associations with conventional cardiovascular and renal risk factors were revealed.

$\alpha$ - and $\pi$-GST excretions were similar in patients with diabetes versus controls. Furthermore, levels were similar among normo-, micro- and macroalbuminuric patients.

These findings are in accordance with previous cohort studies that have shown that elevated $\pi$-GST seems to be superior to $\alpha$-GST in the early detection of acute kidney injury in different acute clinical settings [16-19]. Although DN is usually considered a glomerular disease characterized by elevated UAER, not only glomerular damage but also tubulointerstitial damage and inflammation are important factors in the pathophysiology of DN $[8,20]$. Recently, we have shown that the urinary tubulus markers neutrophil gelatinase-associated lipocalin and liver fatty acid-binding protein were increased with DN, even before the development of micro- or macroalbuminuria in patients with type 1 diabetes [9-11]. Therefore, new markers predicting and grading DN are necessary to precipitate early treatment and prevent disease progression.

The literature on urinary GST markers in patients with diabetes is limited, especially in adult type 1 diabetic patients. Cawood et al. [21] reported that the proportion of patients with diabetes with abnormal results of $\pi$-GST increased across the normo-, micro- and macroalbuminuria groups. This is in accordance with our previous findings on markers of tubular damage in type 1 diabetes, but in contrast to the current GST findings. This was, however, in a cohort of primarily type 2 diabetic patients with a relatively short duration of diabetes.

Conversely, in a study of children with type 1 diabetes, Holmquist and Torffvit [22] discovered that $\alpha$-GST and $\pi$-GST excretion rates were significantly lower among children with diabetes compared to controls. Moreover, in patients with diabetes, a lower $\alpha$-GST excretion rate was associated with longer diabetes duration, poor metabolic control, lower GFR and higher UAER, whereas $\pi-G S T$ concentrations were not associated with renal parameters. In the setting of acute tubular damage, GST levels increase, hence it was speculated that the lower excretion rates of $\alpha$-GST with a declining GFR could potentially be due to both proximal and distal tubular atrophy associated with chronic renal damage in patients with type 1 diabetes. This is, however, not supported by our findings and, furthermore, we were not able to replicate the previous associations between GSTs, $\mathrm{HbA}_{1 \mathrm{c}}$ and UAER. Inhibition of the RAAS has improved the prognosis for DN and has been an important factor in decreasing the prevalence of ESRD [23]. Intervention with RAAS blockers is known to reduce both blood pressure and albumin excretion, and the reduction in UAER is a predictor of reduced decline in kidney function [24]. In our current study, 35\% of the normoalbuminuric patients and more than $90 \%$ of patients with elevated UAER were on AHT, predominantly RAAS-blocking agents, which could interfere with the association between UAER and GST markers of tubular damage.

It is likely that measurements of urinary $\alpha$ - and $\pi$-GST possess a higher diagnostic value in patients with acute renal injury, whereas the role in chronic conditions, including diabetes, is not clear. During tubular damage, the GST markers are released rapidly into the urine and due to their expression in distinct parts of the nephron, the urinary levels of the markers 
allow for localization of the tubular injury [13]. However, the findings in our study suggest that neither $\alpha$ - nor $\pi$-GST is associated with renal parameters, hence it seems unlikely for these biomarkers to contribute to the existing panel of urinary risk markers in DN.

In conclusion, GST/creatinine ratios were similar in controls and patients with type 1 diabetes and not related to the albuminuria degree. We did not find an association between GST/creatinine ratios and estimated renal function. However, the existing knowledge on $\alpha$ and $\pi$-GST in diabetes is still limited and the significance of an increased or decreased urinary excretion of $\alpha$ - and $\pi$-GST needs further investigation.

\section{Acknowledgement}

The authors would like to thank Argutus Medical Limited - EKF Diagnostics, Dublin, Ireland.

\section{Disclosure Statement}

None of the authors declare any conflicts of interest.

\section{References}

1 Rossing P: The changing epidemiology of diabetic microangiopathy in type 1 diabetes. Diabetologia 2005; 48: 1439-1444.

-2 Borch-Johnsen K, Kreiner S: Proteinuria: value as predictor of cardiovascular mortality in insulin dependent diabetes mellitus. Br Med J (Clin Res Ed) 1987;294:1651-1654.

- 3 Ismail-Beigi F, Craven T, Banerji MA, Basile J, Calles J, Cohen RM, Cuddihy R, Cushman WC, Genuth S, Grimm RH Jr, Hamilton BP, Hoogwerf B, Karl D, Katz L, Krikorian A, O’Connor P, Pop-Busui R, Schubart U, Simmons D, Taylor H, Thomas A, Weiss D, Hramiak I: Effect of intensive treatment of hyperglycaemia on microvascular outcomes in type 2 diabetes: an analysis of the ACCORD randomised trial. Lancet 2010;376:419-430.

-4 Parving HH, Brenner BM, Cooper ME, de Zeeuw D, Keane WF, Mitch WE, Remuzzi G, Snapinn SM, Zhang Z, Shahinfar S: Effect of losartan on renal and cardiovascular complications of patients with type 2 diabetes and nephropathy. Ugeskr Laeger 2001;163:5514-5519.

-5 Gross JL, de Azevedo MJ, Silveiro SP, Canani LH, Caramori ML, Zelmanovitz T: Diabetic nephropathy: diagnosis, prevention, and treatment. Diabetes Care 2005;28:164-176.

6 Caramori ML, Fioretto P, Mauer M: The need for early predictors of diabetic nephropathy risk: is albumin excretion rate sufficient? Diabetes 2000;49:1399-1408.

7 Molitch ME, Steffes M,Sun W, Rutledge B, Cleary P, de Boer IH,Zinman B, Lachin J: Developmentand progression of renal insufficiency with and without albuminuria in adults with type 1 diabetes in the diabetes control and complications trial and the epidemiology of diabetes interventions and complications study. Diabetes Care 2010;33:1536-1543.

8 Gilbert RE, Cooper ME: The tubulointerstitium in progressive diabetic kidney disease: more than an aftermath of glomerular injury? Kidney Int 1999;56:1627-1637.

-9 Nielsen SE, Schjoedt KJ, Astrup AS, Tarnow L, Lajer M, Hansen PR, Parving HH, Rossing P: Neutrophil Gelatinase-Associated Lipocalin (NGAL) and Kidney Injury Molecule 1 (KIM1) in patients with diabetic nephropathy: a cross-sectional study and the effects of lisinopril. Diabet Med 2010;27:1144-1150.

10 Nielsen SE, Sugaya T, Hovind P, Baba T, Parving HH, Rossing P: Urinary liver-type fatty acid-binding protein predicts progression to nephropathy in type 1 diabetic patients. Diabetes Care 2010;33:1320-1324.

-11 Nielsen SE, Sugaya T, Tarnow L, Lajer M, Schjoedt KJ, Astrup AS, Baba T, Parving HH, Rossing P: Tubular and glomerular injury in diabetes and the impact of ACE inhibition. Diabetes Care 2009;32:1684-1688.

12 Sundberg AG, Appelkvist EL, Backman L, Dallner G: Urinary pi-class glutathione transferase as an indicator of tubular damage in the human kidney. Nephron 1994;67:308-316.

-13 Dieterle F, Sistare F: Biomarkers of acute kidney injury; in Vaidya VS, Bonventre JV (eds): Biomarkers: In Medicine, Drug Discovery, and Environmental Health. Hoboken, Wiley, 2010, pp 237-279.

14 Theilade S, Lajer M, Persson F, Joergensen C, Rossing P: Arterial stiffness is associated with cardiovascular, renal, retinal, and autonomic disease in type 1 diabetes. Diabetes Care 2013;36:715-721. 
15 K/DOQI clinical practice guidelines for chronic kidney disease: evaluation, classification, and stratification. Am J Kidney Dis 2002;39:S1-S266.

-16 Koyner JL, Vaidya VS, Bennett MR, Ma Q, Worcester E, Akhter SA, Raman J, Jeevanandam V, O'Connor MF, Devarajan P, Bonventre JV, Murray PT: Urinary biomarkers in the clinical prognosis and early detection of acute kidney injury. Clin J Am Soc Nephrol 2010;5:2154-2165.

-17 Seabra VF, Perianayagam MC, Tighiouart H, Liangos O, dos Santos OF, Jaber BL: Urinary alpha-GST and pi-GST for prediction of dialysis requirement or in-hospital death in established acute kidney injury. Biomarkers 2011;16:709-717.

-18 Westhuyzen J, Endre ZH, Reece G, Reith DM, Saltissi D, Morgan TJ: Measurement of tubular enzymuria facilitates early detection of acute renal impairment in the intensive care unit. Nephrol Dial Transplant 2003;18: 543-551.

19 Susantitaphong P, Perianayagam MC, Tighiouart H, Kouznetsov D, Liangos O, Jaber BL: Urinary alpha- and pi-glutathione s-transferases for early detection of acute kidney injury following cardiopulmonary bypass. Biomarkers 2013;18:331-337.

20 Parving HH, Mauer M, Ritz E: Diabetic nephropathy; in Brenner BM (ed): Brenner \& Rector's The Kidney. Philadelphia, WB Saunders, 2008, pp 1265-1298.

-21 Cawood TJ, Bashir M, Brady J, Murray B, Murray PT, O’Shea D: Urinary collagen IV and piGST: potential biomarkers for detecting localized kidney injury in diabetes - a pilot study. Am J Nephrol 2010;32:219-225.

22 Holmquist P, Torffvit O: Tubular function in diabetic children assessed by Tamm-Horsfall protein and glutathione S-transferase. Pediatr Nephrol 2008;23:1079-1083.

23 Keane WF, Zhang Z, Lyle PA, Cooper ME, de Zeeuw D, Grunfeld JP, Lash JP, McGill JB, Mitch WE, Remuzzi G, Shahinfar S, Snapinn SM, Toto R, Brenner BM: Risk scores for predicting outcomes in patients with type 2 diabetes and nephropathy: the RENAAL study. Clin J Am Soc Nephrol 2006;1:761-767.

-24 Rossing P, Hommel E, Smidt UM, Parving HH: Reduction in albuminuria predicts diminished progression in diabetic nephropathy. Kidney Int Suppl 1994;45:S145-S149. 